\title{
Signal-food contingency and signal frequency in a continuous trials auto-shaping paradigm
}

\author{
J. GIBBON, C. LOCURTO, and H. S. TERRACE \\ N.Y.S. Psychiatric Institute and Columbia University, New York, New York 10027
}

\begin{abstract}
Five groups of pigeons were studied in an auto-shaping procedure which programmed two types of trials represented by hues on the response key. Each signal was separated by a brief intertrial interval. Three groups were studied with a positive correlation between one of the signals and food (contingent groups). They differed with respect to the frequency with which the positive signal appeared. Two noncontingent groups were studied in which the correlation between the signals and food was eliminated by programming food with the same probability following either signal. One noncontingent group had a high density of reinforcement produced by adding reinforcement in the other signal, at the same rate as programmed in the positive signal for the contingent groups. The other noncontingent group experienced the same number of reinforcements in the session as the contingent group with the least frequent positive trial, but these reinforcements were distributed with equal probability across the signals. Birds in the contingent groups with intermediate or infrequent positive signals all acquired reliable pecking, with acquisition most rapid for the infrequent signal. Maintained responding covaried with the speed of acquisition. No birds in the noncontingent groups showed reliable responding. Birds in the contingent group with a frequent positive signal (approximately $3 / 4$ of the session), also showed no reliable pecking. This result suggests that more than one noncontingent group is informative for assessing the role of differential reinforcement probability in the acquisition of auto-shaped keypecking. In particular, a noncontingent group which controls for the frequency of reinforced trials is an appropriate reference group.
\end{abstract}

An increasingly large number of experiments have confirmed Brown and Jenkins' (1968) demonstration that a pigeon will learn to peck a response key when key illuminations signal food presentations (see Hearst \& Jenkins, 1974 , or Schwartz \& Gamzu, in press, for reviews). One source of interest in the phenomenon stems from a biological analysis of consummatory behavior in birds and other species, and the relation of the form of the response - its "nonarbitrary" nature to the motivation systems involved (e.g., Jenkins \& Moore, 1973; Moore, 1973).

Another active area of investigation derives from the early demonstration by Williams and Williams (1969) that the auto-shaped keypeck is reliably maintained under some circumstances even when the peck itself prevents food presentation (e.g., Barrera, 1974; Herrnstein \& Loveland, 1972; Schwartz \& Williams, 1972a, 1972b). This paradoxical phenomenon demonstrates the power of the autoshaping procedure, since it appears to overwhelm response-reinforcer contingencies which would tend to suppress responding.

The present report focuses on a third area of interest, namely the signal-food contingency itself. The term "contingency" in this context means a predictive relationship between signal and food rather than simply a contiguous relationship. Gamzu and Williams (1971) were the first to demonstrate that predictiveness was important in the auto-shaping phenomenon. In their

This research was supported by NSF Grant GB34095 and NIH Grant MH25070-01 (J. Gibbon, P. I.) and NSF Grant 30781 and NIH Grant HD00930 (H. S. Terrace, P. I.). Reprints may be obtained from J. Gibbon, Psychiatric Institute, 722 West 168th Street, New York, N.Y. 10032. study, as in the present experiment, food was unrelated to responding, and thus its delivery was noncontingent with respect to behavior. Food delivery in their study was contingent with respect to key illumination for one group, and noncontingent with respect to key illumination for another. In the contingent procedure, food was delivered on a variable time schedule whenever the key was illuminated, but not when the key was dark. The noncontingent procedure simply lifted this stricture on intertrial interval (ITI) periods and allowed food to be delivered at the same rate when the key was dark. Gamzu and Williams found that responding on the key occurred only in birds exposed to the contingent procedure.

Their experiment was an adaptation of Rescorla's (1968, Experiment I) examination of contingent and noncontingent signal-shock pairing procedures with rats. However, Rescorla studied two different noncontingent procedures while Gamzu and Williams studied one. The noncontingent procedure studied by Gamzu and Williams added reinforcements in what had previously been the ITI, while the alternative would involve simply redistributing reinforcements across signal and nonsignal periods so that the predictiveness of stimulus conditions on the key would remain equal throughout the session. Such a control procedure is an important one if reinforcement density per se is important in autoshaping.

The density with which positive trials occur in time has been shown to have considerable importance for the speed of acquisition. Terrace, Gibbon, Farrell, and Baldock (1975) studied the intertrial interval parameter 


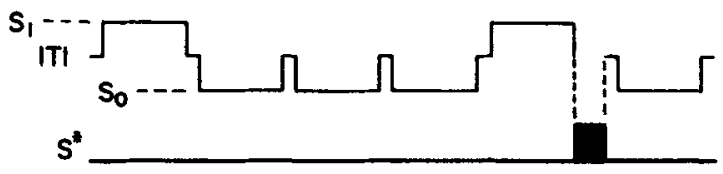

Figure 1. Schematic representation of the continuous trials paradigm. Trial periods, represented by different hues on the key, are labeled $S_{0}$ and $S_{1}$ and are separated by a brief ITI. Reinforcement ( $\left.S^{*}\right)$ occurs with some probability at the end of either trial. In this example, reinforcement occurs after the second $S$, trial.

in a discrete trial auto-shaping paradigm and found that very long intertrial intervals resulted in very rapid acquisition, while frequent reinforcement at short intertrial intervals resulted in very slow acquisition or no acquisition of keypecking. More recently, Farrell and Terrace (1974) have shown that lowering reinforcement probability in the presence of the signal retards acquisition. Thus, when reinforcement density is increased by increasing reinforcement probability in the signal, auto-shaping is facilitated, while if reinforcement density is increased by decreasing the time between positive trials, auto-shaping is retarded.

The present experiment examines these variables in a "continuous trials" context. The session is broken up into trial periods of two different kinds, represented by different hues on the response key and separated by a brief "true" intertrial interval. This procedure allows for negative trials which are valid predictors of no reinforcement but which have equal salience with positive trials. In the more usual discrete trial procedure, it is the intertrial interval which is the valid predictor of no food, while in the present continuous trials procedure, the length of the intertrial interval corresponds to the frequency of negative trials. Reinforcement rate in the presence of the positive signal translates in this context into reinforcement probability.

A later report by Gamzu and Williams (1973) demonstrated that delivering reinforcement only during dark key periods, which occupied three quarters of the session, also resulted in no keypecking. This procedure functionally defined the dark key periods as the positive signal. This translates into a contingent procedure in our paradigm with a greatly increased frequency of positive trials. We will see that the salience differences between the two situations may not be the critical variable in the observation of no acquisition. Rather, the high frequency of positive trials alone, even with a salient "auto-shapeable" signal, may suffice to retard keypecking.

In the present experiment, an intermediate signal frequency condition was studied as well. This allowed us to obtain systematic data on the positive signal frequency effect in our continuous trials paradigm.

\section{METHOD}

Subjects

The subjects were twenty White Carneaux cocks approximately 1 year in age. Each subject was experimentally naive and was maintained at $80 \%( \pm 3 \%)$ of its ad-lib weight.

\section{Apparatus}

The test chamber used in both experiments was a converted Coleman ice chest ( $80 \mathrm{q}$ capacity). The subjects' portion of the chamber was $29 \mathrm{~cm}$ in height, $32.4 \mathrm{~cm}$ wide, and $33 \mathrm{~cm}$ deep. Three walls and the ceiling were white molded plastic. The test panel included a round hole $2.54 \mathrm{~cm}$ in dia behind which was placed a single pigeon key (Lehigh Valley No. 121-06) centered $22 \mathrm{~cm}$ above the floor. The opening to a grain feeder (Lehigh Valley No. 121-08) was located $8 \mathrm{~cm}$ directly below the key. When operated, the feeder was illuminated by a $28-\mathrm{V}$ incandescent bulb (GE 1829). Stimuli were projected to the back of the key via an IEE projector (Grason-Stadler No. 44). The intensities of the three colors were as follows: red 1.30, green 1.60 , yellow $1.95 \log \mathrm{fL}$.

Chamber illumination was provided by a $10-\mathrm{W}$ house lamp located on the ceiling opposite to the test panel. White masking noise was provided continuously in the chamber.

\section{Procedure}

Prior to the first auto-shaping session, all subjects received magazine training. This training included a criterion that all subjects eat from the feeder within $1.5 \mathrm{sec}$ following its presentation for five consecutive trials after the first 10 feeder presentations. A maximum of 50 feeder presentations were allowed during each magazine training session, with time between presentations programmed via a 20 -sec variable-interval tape. The feeder remained operated for $3.5 \mathrm{sec}$ following the insertion of the subject's head into the feeder opening. A photocell arrangement allowed the recording of head insertions. All subjects were required to pass the criterion twice in four such training sessions.

Within 3 days of completion of magazine training, auto-shaping sessions began. Ten-second trials $\left(S_{1}\right.$ or $\left.S_{0}\right)$ were presented as shown in Figure 1, with $S_{1}$ and $S_{0}$ either red or green. Color assignment was counterbalanced across subjects within each group. The brief 1.5-sec ITI was always yellow. When appropriate, the $S_{1}$ signal is regarded as positive and its probability is specified by $P\left(S_{1}\right)=1-P\left(S_{Q}\right)$. Reinforcement probability in either signal is specified by $P_{1}=P\left(S^{*} / S_{1}\right)$, and $\mathbf{P}_{0}=\mathbf{P}\left(\mathrm{S}^{*} / \mathrm{S}_{0}\right)$. Subjects were randomly assigned to one of the five groups described below in termis of events per session.

(1) Contingent I - Infrequent signal positive $(N=8)$. Six of the $24 \mathrm{~S}_{1}$ signals were followed by reinforcement and none of the $76 \mathrm{~S}_{0}$ signals were followed by reinforcement $\left[P_{0}=0\right.$, $\left.P_{1}=0.25, P\left(S_{1}\right)=0.24\right]$.

(2) Contingent II - Equal signal frequencies $(\mathrm{N}=12,4$ subjects with green positive and 8 subjects with red positive). Twelve of $48 S_{1}$ trials were followed by reinforcement and none of $48 S_{0}$ trials were followed by reinforcement $\left[P_{0}=0\right.$, $\left.P_{1}=0.25, P\left(S_{1}\right)=0.5\right]$.

(3) Contingent III - Frequent signal positive $(\mathrm{N}=8)$. Nineteen of $76 S_{1}$ trials were followed by reinforcement and none of $24 \mathrm{~S}_{0}$ trials were followed by reinforcement $\left[\mathrm{P}_{0}=0\right.$, $\left.P_{1}=0.25, P\left(S_{1}\right)=0.76\right]$.

(4) Noncontingent I - Low density reinforcement $(N=4)$. Two of $24 \mathrm{~S}_{1}$ trials and 4 of $76 \mathrm{~S}_{0}$ trials were followed by reinforcement $\left[P_{0}=0.053, P_{1}=0.083, P\left(S_{1}\right)=0.24\right]$. These reinforcement frequencies thus represent only an approximately noncontingent condition. 
Table 1

Acquisition Measures for All Groups

\begin{tabular}{|c|c|c|c|c|c|c|c|c|}
\hline \multirow{2}{*}{$\begin{array}{l}\text { Condition } \\
\text { Contingent I } \\
\text { (Infrequent signal } \\
\text { reinforced) }\end{array}$} & \multirow{2}{*}{$\begin{array}{c}\begin{array}{c}\mathrm{P}_{0} \\
\left(\mathrm{~S} / \mathrm{S}_{0}\right)\end{array} \\
.00 \\
(0 / 76)\end{array}$} & \multirow{2}{*}{$\begin{array}{c}\begin{array}{c}P_{1} \\
\left(\mathrm{~S}^{*} / \mathrm{S}_{1}\right)\end{array} \\
25 \\
(6 / 24)\end{array}$} & \multirow{2}{*}{$\begin{array}{l}\mathrm{P}\left(\mathrm{S}_{1}\right) \\
(\mathrm{ITI} \text { in } \\
\mathrm{sec})\end{array}$} & \multicolumn{2}{|c|}{$\begin{array}{l}\text { Relative Frequency of } \\
\text { Subjects Emitting at } \\
\text { Least One Response }\end{array}$} & \multicolumn{2}{|c|}{$\begin{array}{l}\text { Reinforcements Prior } \\
\text { to First Peck to } S_{1} \\
\text { Median } \quad \text { Range }\end{array}$} & \multirow{2}{*}{$\begin{array}{c}\begin{array}{c}\text { Mean } \\
\text { Responses } \\
\text { Per Bird }\end{array} \\
165.5\end{array}$} \\
\hline & & & & $8 / 8$ & $(100 \%)$ & 44.0 & $8-108$ & \\
\hline $\begin{array}{l}\text { Contingent II } \\
\text { (Equal signal } \\
\text { frequencies) }\end{array}$ & $\begin{array}{l}.00 \\
(0 / 48)\end{array}$ & $\begin{array}{l}.25 \\
(12 / 48)\end{array}$ & $\begin{array}{l}.50 \\
(13)\end{array}$ & $12 / 12$ & $(100 \%)$ & 151.0 & $12-254$ & 92.08 \\
\hline $\begin{array}{l}\text { Contingent IIl } \\
\text { (Frequent signal } \\
\text { reinforced) }\end{array}$ & $\begin{array}{l}.00 \\
(0 / 24)\end{array}$ & $\begin{array}{l}.25 \\
(19 / 76)\end{array}$ & $\begin{array}{l}.76 \\
(5.3)\end{array}$ & $5 / 8$ & $(62.5 \%)$ & 385.0 & $354-514$ & .0 \\
\hline $\begin{array}{l}\text { Noncontingent I } \\
\text { (Low density) }\end{array}$ & $\begin{array}{l}.05 \\
(4 / 76)\end{array}$ & $\begin{array}{l}.08 \\
(2 / 24)\end{array}$ & .24 & $2 / 4$ & $(50 \%)$ & $19.0^{\dagger}$ & $9-29$ & 1.5 \\
\hline $\begin{array}{l}\text { Noncontingent Il } \\
\text { (High density) }\end{array}$ & $\begin{array}{l}.25 \\
(19 / 76)\end{array}$ & $\begin{array}{l}.25 \\
(6 / 24)\end{array}$ & .76 & $4 / 8$ & $(50 \%)$ & $212.0 \dagger$ & $46-304$ & 3.7 \\
\hline \multicolumn{9}{|c|}{ Farrell and Terrace, 1974} \\
\hline \multicolumn{2}{|l|}{$50-\mathrm{sec}$ ITI } & $\begin{array}{l}.33 \\
(25 / 75)\end{array}$ & $\begin{array}{l}.19 \\
(50)\end{array}$ & $4 / 4$ & $(100 \%)$ & 74.0 & & \\
\hline \multicolumn{2}{|l|}{ 15-sec ITI } & $\begin{array}{l}.33 \\
(25 / 75) \\
\end{array}$ & $\begin{array}{l}.43 \\
(15) \\
\end{array}$ & $4 / 4$ & $(100 \%)$ & 151.0 & & \\
\hline
\end{tabular}

fFirst peck to either signal.

(5) Noncontingent II - High density reinforcement $(N=8)$. Nineteen of $76 \mathrm{~S}_{1}$ trials and 6 of $24 \mathrm{~S}_{0}$ trials were followed by reinforcement $\left[\mathrm{P}_{0}=0.25, \mathrm{P}_{1}=0.25, \mathrm{P}\left(\mathrm{S}_{1}\right)=0.76\right]$.

The temporal parameters and probability values were chosen so that the conditions for groups Contingent I, Contingent III, and Noncontingent II approximated conditions studied by Gamzu and Williams $(1971,1973)$.

In all conditions, responses to the key were recorded but had no effect on the sequence or duration of the stimuli. Experimental sessions were generally conducted seven days a week.

\section{RESULTS}

\section{Acquisition}

Table 1 presents summary data on acquisition for all groups. The conditions are specified in the left columns. The columns for the conditional probability of food in the presence of $S_{0}$ and $S_{1}$ also give the absolute frequencies of reinforced trials and total trials per session in parentheses underneath each probability value. For example, Contingent I has $P_{1}=0.25$, with 6 reinforced trials out of a total of 24 . The next column shows the probability of an $S_{1}$ trial and below that, in parentheses, the average intertrial interval in seconds. The next column presents the relative frequency of subjects emitting at least one key response over the course of 20 sessions of training. All subjects in the Contingent $I$ and II groups acquired responding. The frequent signal positive condition, Contingent III, produced fewer birds pecking and the noncontingent conditions still fewer. The next columns show the median and range of reinforcements prior to the first peck. The Contingent I subjects acquired fairly rapidly (median of 44 reinforcements), and Contingent II less rapidly (median of 151 reinforcements). Only five of the eight subjects of the Contingent III group responded. For those subjects which pecked, the median number of reinforcements prior to the first response was 385 . Emission of a keypeck required fewer reinforcements in the case of the two noncontingent groups than was needed by the Contingent III group. The low density noncontingent group responded earlier than the high density group.

The pecking observed in the Contingent III and the Noncontingent I and II groups was sporadic, emitted at low rates, and was not maintained as training proceeded. Responding of all of these subjects tended to drop out after a few sessions and never reached reliable levels. The last column presents mean responses per subject cumulated over the first 15 sessions of training. It shows that the only birds pecking reliably are those in the Contingent.I and II conditions. No birds pecked the key in the first 15 sessions for the Contingent III group, and pecking was very infrequent for the last two noncontingent groups. The subjects in Contingent III which did show some responding did so only after 15 sessions and the response rates never exceeded two responses per bird per session. The mean responses per subject over the first 15 sessions appears to be different for the first two contingent groups. However, this difference is not statistically reliable, and is solely due to a larger proportion of birds which acquired late in the Contingent II group. In contrast, the median number of reinforcements prior to the first peck of the Contingent I and II groups is significantly different $(t=4.01, d f=18, p<.0005)$.

At the bottom of the table are data trom a study reported by Farrell and Terrace (1974). They ran probabilistic reinforcement at several ITI values with a 
discrete trial procedure in which the ITI period was represented by a dark key. The conditions closest to the ones in the present experiment are shown. $P\left(S_{1}\right)$ is specified as though these procedures had been generated by our continuous trials procedure. The procedure closest to our Contingent I condition comprised somewhat less frequent positive trials (about 0.2 of the session) and a somewhat higher rate of reinforcement in the signal. Their birds acquired more slowly than ours. The other comparable group for which the signal frequency was quite close to our equal frequency condition acquired after the same number of reinforcements.

From these acquisition data it is clear that (1) Noncontingent conditions produce no sustained pecking, although low density reinforcement conditions result in some early pecks to the key. (2) The frequent signal positive condition also results in no sustained pecking. (3) It is only when reinforcement is both differential with respect to $S_{1}$ rather than $S_{0}$, and when $S_{1}$ is at least as infrequent as $S_{0}$, that pecking is sustained. (4) The positive trial frequency effect is in the same direction as previous reports of ITI effects, and our data show somewhat more rapid acquisition.

Data from the other two groups that acquired responding in the present study and from two other studies using comparable parameters are shown in Figure 2. Median reinforcements prior to the first peck are represented on the ordinate and the probability of the positive trial is shown on the abscissa. The scale at the top of the figure shows the corresponding ITI values. Terrace, Gibbon, Farrell, and Baldock (1975) studied acquisition under a procedure in which each $10-\mathrm{sec}$ trial period, represented by a lit key, was reinforced, and dark ITI periods intervened between trials. These authors reported no pecking for ITI values of $5 \mathrm{sec}$ or less, and in our continuous trials context, this translates to a probability of positive signals of about 0.7 or more. This cutoff is indicated by the dashed vertical line in Figure 2. Our Contingent III group which did not acquire exceeds this value also. For positive signals less frequent than this, acquisition was found to be a power function of the ITI. This function, translated to the trial frequency representation, is shown by the smooth curve in the figure. Farrell and Terrace's data for probability of reinforcement in the positive signal of $P_{1}=0.33$ is shown by filled squares. When the positive signal is sufficiently infrequent $\left[P\left(S_{1}\right)=0.1\right]$, approximately 20 reinforced peckings are all that is required to produce pecking, and data are comparable to those for $100 \%$ reinforcement (Terrace et al, 1975) at this low frequency. However, for intermediate values of the probability of $S_{1}$, retarded acquisition is evident in the $P_{1}=0.33$ condition as compared with the $100 \%$ reinforcement function.

The data we obtained are indicated by filled circles.
Our infrequent signal case resulted in rapid acquisition comparable to $100 \%$ reinforcement and our equal signal frequency condition produced acquisition comparable to the $P_{1}=0.33$ reinforcement probability condition.

Thus, the paradigm we have studied, which programmed explicit negative signals, results in more rapid acquisition than would be expected from data on partial reinforcement or $100 \%$ reinforcement when the ITI is represented by a dark key. At a frequency of the positive signal comparable to our Contingent I group, Farrell and Terrace found that a reinforcement probability of 0.33 retarded acquisition relative to $100 \%$ reinforcement. However, our birds acquired at rates comparable to $100 \%$ reinforcement groups. Similarly, while acquisition was retarded in our Contingent II group, it nevertheless acquired about as fast as Farrell and Terrace's group with a comparable ITI but a higher reinforcement probability. Thus, it seems that the continuous trials paradigm facilitates acquisition. A similar though less pronounced facilitation was observed by Terrace et al. (1975) with explicit negative signals.

Response rate and probability are presented on the left and right of Figure 3 for the two contingent groups that acquired responding. Comparable data for the other groups do not exist since no subjects maintained responding. The infrequent signal group is shown in the top panels and the equal signal group below. Both rate and probability measures reflect the acquisition differences observed in the first peck data for these groups. When the positive signal is infrequent, response

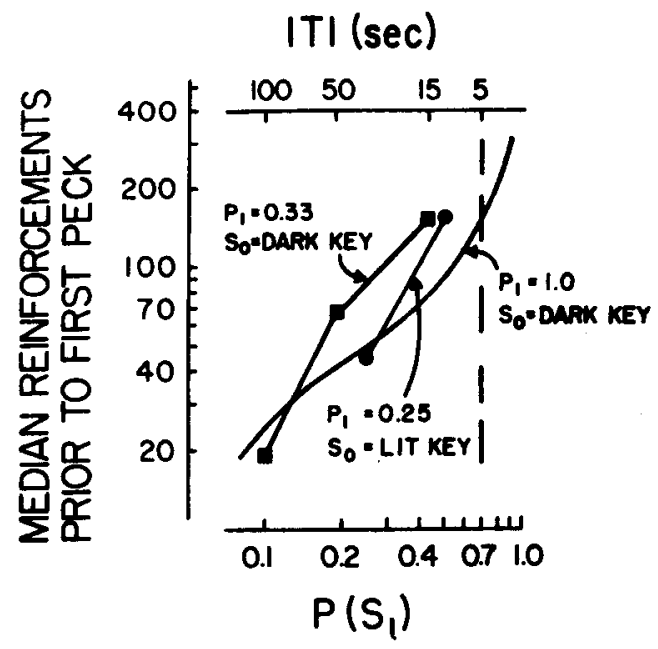

Figure 2. Median reinforcement before the first keypeck to. $S_{1}$, as a function of the frequency of $S_{1}$ trials. The abscissa and ordinate are logged. The lower abscissa scale represents probability of $S_{1}$ occurrence. On the upper axis the corresponding intertrial intervals are shown. These intervals are defined as periods between $S_{1}$ offset and the next subsequent $S_{1}$ onset. Data from Farrell and Terrace (1974) are represented by filled squares and data from Terrace et al. (1975) are represented by the smooth function. 
rates in this signal rise to high levels and responding is reliably maintained in the signal, while when the positive signal is more frequent, response rates are lower and response probability does not exceed about .70 . These relations hold for ITI responding and for responding in $S_{0}$ as well. For the infrequent signal positive condition, response rates in $S_{0}$ remain very low, although some consistently greater than zero proportion of $S_{0}$ trials receive at least one peck. When the positive signal is more frequent, $S_{0}$ responding is lower, but still discernible. The open triangles represent responding in the 1.5-sec lit ITI periods which intervened between each $10-\sec$ trial. Substantial responding occurs here at levels considerably below positive signal responding, but above negative signal responding. In the usual auto-shaping paradigm in which ITI periods are represented by a dark key, ITI responding may develop early in training, but generally subsides within several sessions (Baldock \& Gibbon, 1974; Farrell \& Terrace, 1974; Gonzalez, 1972). In our condition in which most of what is commonly referred to as the ITI is represented by a negative signal, and brief lit-key "true" ITI periods intervene between all signals, the brief ITI supported responding throughout the observation period
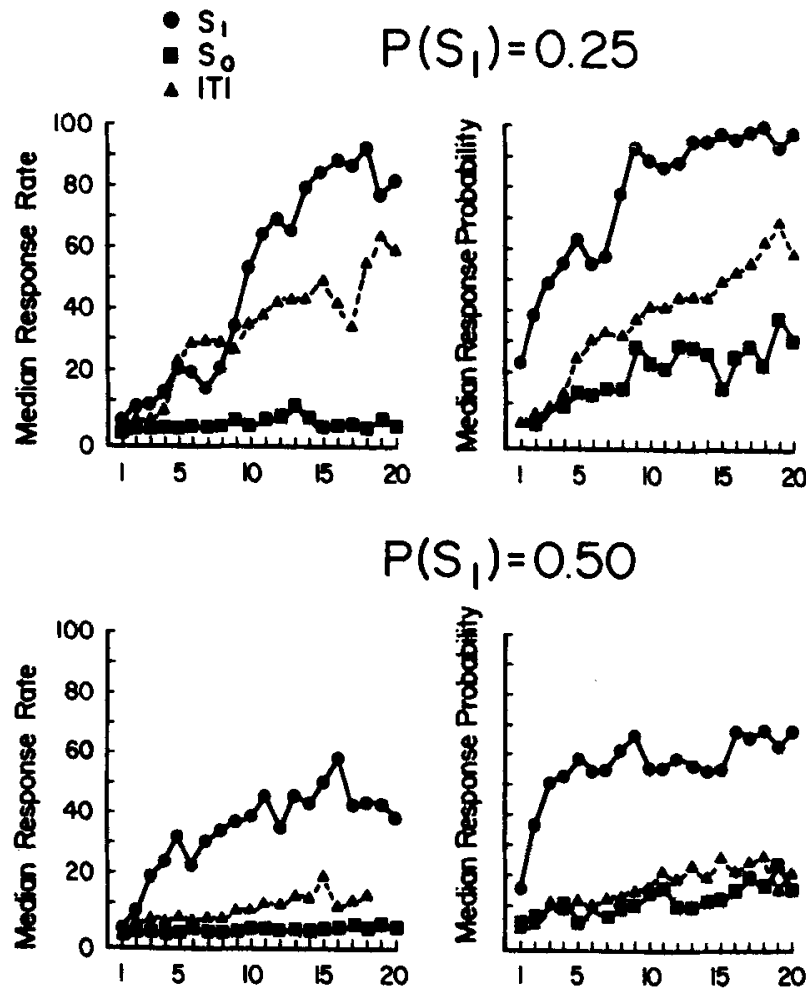

SESSIONS RE: SESSION WITH FIRST RESPONSE

Fizure 3. Median responses per minute (left panels) and medinn response probability (right panels) for $S_{1}$ (fillod circles), $S_{0}$ (filled squares), and the ITI signal (triangles). The upper two panels are data from the infrequent signal positive group and the lower two panels are data from the equal frequency group.

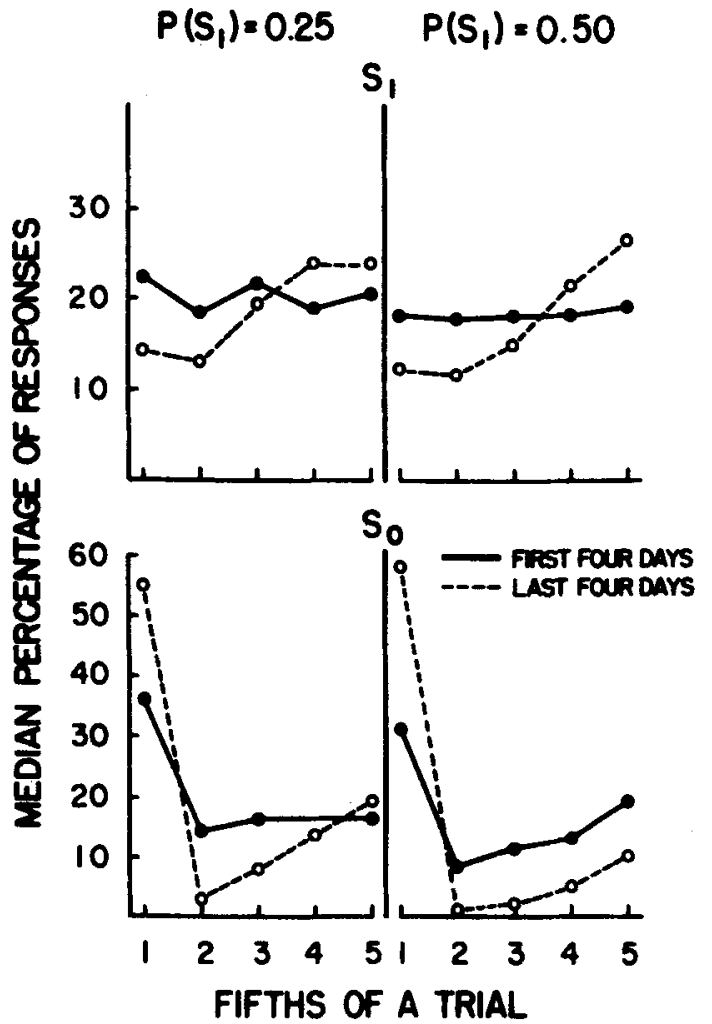

Figure 4. Proportion of tesponding is successive fifths of the tribl signals. The upper two panels reprecent responding in $S_{1}$ for the infrequent signal group (on the left) and for the equal signal frequency group (on the right). Data from the first four days of responding are represented by filled circles and data from the hat four days are represented by open circles The corresponding data for the negative signal $\left(S_{0}\right)$ are shown in the bottom two panels (note the compressed scale).

of 20 sessions. Indeed, ITI responding appeared to be increasing throughout the 20 sessions of training for Contingent I subjects. With the equal signal frequency condition ITI responding was about comparable to negative signal responding by the end of training.

Responding was recorded in successive fifths of the signal periods for both positive and negative signals. The median per .cent of responding in each fifth is shown in Figure 4. The upper two panels represent the responding in the positive signal for Contingent I (left panel) and Contingent II (right panel). Responding in the negative signal for these conditions is shown directly below. The filled points represent data from the first four days of pecking and the open points data from the last four days (Days 16-20). A flat function at the $20 \%$ level represents no temporal discrimination of the signal duration and this is what is seen in the first 4 days for the positive signal under both signal frequency conditions. After 20 sessions of training, however, some acceleration in responding towards the end of the positive signal is evident. Birds evidently wait through the early portion of the signal and emit more responses towards the time when reinforcement is due. 
Table 2

Responding as a Function of Color Assignment

\begin{tabular}{|c|c|c|c|c|}
\hline & \multicolumn{2}{|c|}{$P\left(S_{1}\right)=.24$} & \multicolumn{2}{|c|}{$\mathrm{P}\left(\mathrm{S}_{1}\right)=.50$} \\
\hline & $\begin{array}{c}S_{1}= \\
\text { Green }\end{array}$ & $\begin{array}{l}S_{1}= \\
\text { Red }\end{array}$ & $\begin{array}{c}S_{1}= \\
\text { Green }\end{array}$ & $\begin{array}{l}S_{1}= \\
\text { Red }\end{array}$ \\
\hline $\begin{array}{l}\text { Median } S^{*} \text { s before } \\
\text { first } S_{2} \text { peck }\end{array}$ & 45.0 & 43.0 & 159.0 & 133.0 \\
\hline $\begin{array}{l}\text { Median } S_{1} \text { response } \\
\text { probability in last } \\
\text { five sessions }\end{array}$ & .99 & .94 & .35 & .96 \\
\hline $\begin{array}{l}\text { Median } S_{1} \text { responses } \\
\text { per min in last } \\
\text { five sessions }\end{array}$ & 127.1 & 42.5 & 4.1 & 77.9 \\
\hline
\end{tabular}

Responding in the negative signal is more complex. In both signal frequency conditions, and early as well as late in training, there is a high proportion of responding in the first $2 \mathrm{sec}$ of the negative trial. With prolonged training, this percentage increases above $50 \%$ for both signal frequency conditions. The remainder of the trial appears to have a scalloped character after sufficient training so that there is some increment from the second fifth to the last fifth. This increment is not observed in the infrequent signal positive condition early in training, although early in training in the equal signal frequency condition there is some suggestion of this acceleration.

As noted earlier, the color of the positive signal was either red or green and color assignment was counterbalanced within groups. There were some effects due to color assignment which appeared when the positive and negative signals were equally frequent. In Table 2, acquisition and maintenance data are presented as a function of color assignment for Contingent I (left two columns) and II (right two columns). There is no difference between colors for the acquisition measure, however, for the equal frequency group, a color effect emerges in maintained responding. Response probability and response rate are lower for green than for red in this group. An analysis of variance was performed with each measure. Acquisition showed a large effect due to frequency of the positive signal $(F=9.82, \mathrm{df}=1 / 16$, $\mathrm{p}<.01)$. There was no effect due to color or interaction. The response probability and the response rate showed no main effect due to color or to signal frequency. However, both showed interaction effects (response probability: $F=7.57$, $\mathrm{df}=1 / 16, \mathrm{p}<.025$; response rate: $F=5.88, \mathrm{df}=1 / 16, \mathrm{p}<.05$ ). The interaction effect means that color makes a difference only when $P\left(S_{1}\right)=0.5$. Acquisition is not affected by color but maintenance data show something of a red preference when the positive and negative signals are equally frequent.

\section{DISCUSSION}

The central findings are the positive trial frequency effect and the contingency effect. The data imply that the high density "random control" is not the only baseline appropriate for assessing the power of the signal-food contingency in auto-shaping. The failure to observe acquisition of responding in our frequent signal positive condition shows that a high frequency of positive signals alone was sufficient to inhibit or retard pecking even though there was a correlation between those signals and food. That this correlation was also important was demonstrated by the failure to observe pecking in our low density noncontingent condition. There the $S_{1}$ signal was infrequent enough to support pecking when a contingency between it and food was present, but when that contingency was obliterated by programming (infrequent) reinforcement in the other signal, pecking did not develop. Thus, the contingency between positive trial signals and food, and the frequency of positive trials, interact in the auto-shaping phenomenon. Either variable is sufficiently powerful to inhibit the emergence of auto-shaped pecking, and appropriate values of both are required to observe it.

The color differences we observed parallel some color preference data reported previously (Hermstein \& Loveland, 1972; Jenkins, 1973; Wasserman, 1974) using different hues. Color effects apparently appear under some circumstances and not under others. It is not clear presently to what extent the red color preference observed here might reflect a species-typical response tendency, either aggressive or appetitive in nature. It is noteworthy that the effect of color is seen only when other more powerful variables, e.g., positive trial frequency or contingency, are not at maximal values.

The data on responding in successive portions of the trial make it clear that the initiation of auto-sinaped pecking in our situation does not require accurate timing of when reinforcement delivery occurs. Evidently a binary association between the trial cue and food may be formed without finer discrimination of when within the trial cue period discrimination is to be expected. This finer discrimination appears only with continued training. A temporal discrimination seems to be present also in the negative signal, beyond the period right after the onset. Trial onset per se for the negative signal controls a large proportion of responding, but if responses are to occur later in the trial, they tend to occur more frequently close to the end of the signal.

The strength of responding during the brief $1.5-\mathrm{sec}$ ITI was unexpected. This signal, like $S_{0}$ in the contingent conditions, was never followed by reinforcement, yet responding here was intermediate between responding in the positive and negative signals. Possibly the ITI signal might be construed as relatively more positive than the negative signal since it stands in a trace relationship to food while the negative signal is still further removed temporally from reinforcement. Further study manipulating the degree of trace relationship would be required to clarify this point.

The power of auto-shaping contingencies is 
appropriately reflected in the maintained responding that they engender. However, we observed some keypecking in some birds in every group studied here. When a contingency is either absent or too weak to generate maintained responding, some keypecking may occur briefly and later subside. Some of this responding appears to be nonassociative with respect to the signal-food relationship and may be related to overall reinforcement density. Early keypecking occurred with the low density noncontingent group, while both the frequent signal positive group and the high density noncontingent group showed pecking only after a large number of reinforcements. Early nonassociative pecking may be "pseudoconditioned" responding since it seems to be elicited in the same manner and with the same low frequency as responding observed under the pseudoconditioning control paradigm in our laboratory (Farrell \& Terrace, 1974). Late emergence of low rate responding which is not maintained may be of a different character. For example, the responding that did occur in the Contingent III group occurred exclusively during $S_{1}$ trials.

The somewhat faster acquisition observed in our continuous trials paradigm also may be related to our observation of early nonassociative pecking. More rapid acquisition may reflect recruitment of attention to the key area because of frequent stimulus changes. The lit ITI and the different hues used here may make the area of the key more salient and therefore enhance conditioning. It is worth noting that such a view of salience is not common. More usually a highly salient stimulus is thought of as one which contrasts maximally with its background. It is unfortunate that a term like this may receive such differing interpretations and yet remain plausible as a variable in our theorizing. An unambiguous definition would undoubtedly improve our thinking about attention to cues on a priori grounds.

The central effects that we observed here, of spacing of the positive trial signal, and the contingency between signals and food, are consonant with some features of the Rescorla and Wagner (1972) theory. A quantitative account of predictions from their theory for the present case is beyond the scope of this paper. However, a qualitative argument may be sketched as follows. The contingency between signals and food must be present for associative value to accrue to the positive signal. The reason is that background stimuli (or background stimuli plus an alternative stimulus, as in our case) come to predict reinforcement as well as or better than the trial signal. This argument for an excitatory signal versus background alone is detailed in Rescorla and Wagner (1972) and is readily modified for the present case by the addition of an explicit negative signal.

When a contingency between signal and food is present, the model asserts that associative value gradually accrues to the positive signal. The rate at which associative strength increases varies inversely with the spacing of the positive trial. Long or frequent unreinforced background alone periods (or background plus negative signal in our case) intervening between positive trials mean that correspondingly large decrements in associative strength for the background result. When the positive signal is then superimposed on a low level of background excitatory strength and reinforced, the increment in value is larger than that for frequent positive signals, since the compound is further from its asymptote when more extinction of background stimuli has occurred between positive trials. On this qualitative argument, then, the trial spacing effect is handled by the theory as an increase in the effectiveness of spaced reinforced trials.

The theory also holds, however, that the asy mptote of conditioning depends solely on reinforcement probability and not on ITI. Changing trial spacing simply changes the rate at which that asymptote is approached. In the present experiment, the spacing of trials seems to have a more fundamental effect. For the two groups that showed maintained responding, response rates and response probabilities did not appear to be converging within the limits of our observation. Moreover, in the frequent signal-positive group, subjects did not acquire at all. Some birds in this group did show responding to the positive signal late in training which subsequently disappeared. If associative value were gradually accruing to that signal at a slow rate, one might expect that when differential pecking finally emerged, it would be sustained. Therefore, while the contingency effect and the trial spacing effect are in the appropriate directions according to the theory, the maintenance data and the failure to observe acquisition with one contingent group are not handled by the theory without some modification. Possibly, a distinction between performance and learning might be invoked to accomodate these discrepancies.

An alternative approach stems from Rescorla's (1967) argument on the appropriate control procedures for contingency effects, and Gibbon, Berryman, and Thompson's (1974) extension of the contingency analysis in a metric framework. Again, a quantitative account is beyond the scope of the present paper, but a qualitative description may be sketched. From a correlational point of view, one may argue that both differential reinforcement probability and the spacing of the positive signal modulate the level of contingency. Gibbon et al. argue that root mean square contingency, $\phi$, is an appropriate measure of the level of correlation in associative learning paradigms. They suggest that subjects may be viewed as anticipating or predicting reinforcement, and are sensitive to reduction in error rates produced by attending to the trial signals. $\phi^{2}$ may be interpreted as the relative reduction in such errors of prediction. If subjects are not attending to the trial signals, but predicting food at about the rate at which it occurs overall, their errors of prediction are capable of 
large proportional improvement by attending to the trial signals if food occurs in only one of them. In the present context, $\phi$ increases directly with the difference between $P_{1}$ and $P_{0}$. When $P_{1}=P_{0}$, a noncontingent procedure is programmed and $\phi=0$.

Positive trial spacing also affects the correlation between signals and food. When positive trials are spaced far apart, there is, so to say, more room for errors in prediction than when positive trials occur close in time. The relative reduction in error rates produced by attending to the presence, and particularly the absence, of the positive signal is therefore greater when positive signals are infrequent. Intuitively, correct predictions are rare when reinforcements are rare, and so attending to the signals may produce a more substantial improvement.

On the contingency view, then, responding would be expected to be stronger with infrequent trials and with differential reinforcement rates. This view may be more consistent with our maintenance data. The failure to observe acquisition in the frequent positive trials group may be regarded as a result of the lowered correlation value produced by frequent positive signals. On the other hand, the contingency analysis is presently a broad descriptive approach rather than a dynamic theory. Simply specifying $\phi$ does not tell us how different levels of contingency are translated into behavior. It remains to be seen whether the ideas about subjective prediction imbedded in $\phi^{2}$ are more fundamentally related to associative learning mechanisms.

\section{REFERENCES}

Baldock, M. D., \& Gibbon, J. Trial and intertrial interval durations in the acquisition of auto-shaped key pecking. Paper delivered at the Eastern Psychological Association, 45th Annual Meeting, Philadelphia, Pa., 1974.

Barrera, F. J. Centrigual selection of signal directed pecking. Joumal of the Experimental Analysis of Behavior, 1974, 22, 341-355.

Brown, P. \& Jenkins, H. M. Auto-shaping of the pigeon's key-peck. Journal of the Experimental Analysis of Behavior, $1968,11,1-8$.
Farrell, L., \& Terrace, H. S. Auto-shaping as a function of probability of reinforement. Paper delivered at the Eastern Psychological Association. 45th Annual Meeting, Philadelphia, $\mathrm{Pa}, 1974$.

Gamzu, E., \& Williams, D. R. Classical conditioning of a complex skeletal response. Science, 1971, 171, 923-925.

Gamzu, E., \& Williams, D. R. Associative factors underlying the pigeon's key pecking in auto-shaping procedures. Joumal of the Experimental Analysis of Behavior, 1973, 19, 225-232.

Gibbon, J., Berryman, R., \& Thompson, R. L. Contingency spaces and measures in classical and instrumental conditioning. Journal of the Experimental Analysis of Behavior, 1974, 21, 585-605.

Gonzalez, F. A. Effects of partial reinforcement $(25 \%)$ in an autoshaping procedure. Bulletin of the Psychonomic Society, 1973,2 (5A), 299-301.

Hearst, E., \& Jenkins, H. M. Sign-tracking: The stimulus-reinforcer relation and directed action. Monographs, The Psy chonomic Society, Inc., Austin, Texas, 1974.

Herrnstein, R. J., \& Loveland, D. H. Food-avoidance in hungry pigeons, and other perplexities. Joumal of the Experimental Analysis of Behavior, 1972, 18, 369-383.

Jenkins, H. M. Noticing and responding in a discrimination based on a distinguishing element. Learning and Motivation, 1973. 4, 115-137.

Jenkins, H. M., \& Moore, B. R. The form of the autoshaped response with food or water reinforcers. Journal of the Experimental Analysis of Behavior, 1973, 20, 163-181.

Moore, B. $R$. The role of directed Pavlovian reactions in simple instrumental learning in the pigeon. In R. A. Hinde \& J. S. Hinde (Eds.), Constraints on learning. New York: Academic Press, 1973. Pp. 159-188.

Rescorla, R. A. Probability of shock in the presence and absence of $\mathrm{CS}$ in fear conditioning. Joumal of Comparative and Physiological Psy chology, 1968, 66, 1-5.

Rescorla, R. A. \& Wagner, A. R. A theory of Pavlovian conditioning: Variations in the effectiveness of reinforcement and nonreinforcement. In A. H. Black \& W. F. Prokasy (Eds.) Classical conditioning II. New York: Appleton-CenturyCrofts, 1972. Pp. 64-99;

Scnwartz, B., \& Gamzu, E. Pavlovian control of operant behavior: An analysis of autoshaping and of interactions between multiple schedules of reinforcement. In W. K. Honig \& J. E. R. Staddon (Eds.), Handbook of operant behavior. New York: Prentice-Hall (in press).

Schwartz, B., \& Williams, D. R. The role of the response-reinforcer contingency in negative automaintenance. Journal of the Experimental Analysis of Behavior, 1972, 17, 351-357. (a)

Schwartz, B., \& Williams, D. R. Two kinds of key-peck in the pigeon: Some properties of responses maintained by negative and positive response-reinforcer contingencies. Journal of the Experimental Analysis of Behavior, 1972, 18, 201-216. (b)

Terrace, H. S., Gibbon, J., Farrell, L., \& Baldock, M. D. Temporal factors influencing the acquisition and maintenance of an autoshaped response. Animal Learning \& Behavior, in press.

Wasserman, E. A. Stimulus-reinforcer predictiveness and selective discrimination learning in the pigeon. Joumal of Experimental Psy chology, 1974, 103, 284-297.

Williams, $D, R$, Williams, $H$, Auto-maintenance in the pigeon: Sustained pecking despite contingent non-reinforcement. Journal of the Experimental Analysis of Behavior, 1969, 12, 51 1-520.

(Received for publication February 12, 1975. Revision accepted April 22, 1975.) 